\title{
EFFECT OF FETAL BREATHING MOVEMENTS ON FETAL CARDIAC HEMODYNAMICS
}

\author{
KARIN VAN DER MOOREN, ${ }^{\dagger}$ JURIY W. WladimiroFF ${ }^{\dagger}$ and THEO STIJNEN ${ }^{\ddagger}$ \\ 'Department of Obstetrics \& Gynecology and 'Department of Biostatistics, Academic Hospital Rotterdam- \\ Dijkzigt, Erasmus University Rotterdam, Rotterdam, The Netherlands
}

(Received 14 February 1991; in final form 27 June 1991)

\begin{abstract}
Maximum flow velocity waveforms were studied at atrioventricular and outflow tract level in 12 cases during fetal breathing activity and in 12 cases during fetal apnea matched for maternal and gestational age and maternal parity. Gestational age ranged between 27 and 40 weeks (median 30 weeks). All flow velocity waveforms were obtained using a mechanical sector scanner with a pulsed Doppler system (carrier frequency 3.5 MHz). Time-averaged flow velocities were clearly different between inspiration and expiration at all four recording levels, reflecting changes in venous return as a result of fluctuations in intrathoracic pressure during fetal breathing activity. Percentage change between inspiration and expiration at outflow tract level was positively correlated with gestational age. Time-averaged flow velocity at mitral level and ascending aorta level was significantly higher during fetal breathing activity than during apnea, suggesting increased shunting of blood flow through the foramen ovale. Acceleration time at outflow tract level demonstrated very little change relative to inspiration and expiration.
\end{abstract}

Key Words: Fetal breathing, Blood flow velocity waveforms, Atrioventricular valves, Cardiac outflow tracts.

\section{INTRODUCTION}

Human fetal breathing movements have been observed on ultrasound examination from approximately 10 weeks of gestation onwards (de Vries et al. 1982). Some authors state that the prevalence of fetal breathing increases with advancing gestational age until a maximum at a gestational age of 32 weeks is reached (Natale et al. 1988). In third-trimester fetuses, episodes of continuous fetal breathing movements of more than 10 breaths may be present (Trudinger et al. 1980). Fetal breathing activity has been shown to have a profound effect on fetal hemodynamics. In the lamb fetus, when measured electromagnetically, aortic flow was found to increase by $20 \%$ above the nonbreathing level (Walker 1984). In the human fetus, the mean velocity over time increases during highamplitude fetal breathing movements, both in the umbilical vein and in the descending aorta (Marsal et al. 1984). Recently, it was demonstrated that breathing dependent changes in fetal ductal blood flow velocity

Address correspondence to: Juriy W. Wladimiroff, M.D., Ph.D., Professor of Obstetrics \& Gynecology, Academic Hospital Rotterdam-Dijkzigt, Erasmus University Rotterdam, Dr. Molewaterplein 40,3015 GD Rotterdam, The Netherlands. increase exponentially with advancing gestational age (van Eyck et al. 1990).

In the present study, the following questions were addressed: (1) Are blood flow velocity waveforms at atrioventricular and outflow tract level changed between fetal inspiration and expiration? If so, is this change gestational age-dependent? (2) Is time-averaged velocity during fetal breathing movements different from that observed during apnea?

\section{MATERIAL AND METHODS}

A total of 24 women with normal singleton pregnancies consented to participate in the study. Twelve women were studied in the presence of fetal breathing movements, and the remaining 12 women were examined during fetal apnea. Both groups were matched for maternal and gestational age and maternal parity. Median maternal age was 28 years (range 22-34 years), median gestational age was 30 weeks (range 27-40 weeks), and median maternal parity was 1 (range 0-3). The gestational age was calculated from a reliable menstrual history and early sonographic measurement of fetal crown-rump length or biparietal diameter. Fetal birth weight was between the 10th and 90th percentile for gestational age according to Kloos- 
terman's tables corrected for maternal parity and fetal sex (Kloosterman 1970). All participants were nonsmokers, and no medications were prescribed. All studies were performed $2 \mathrm{~h}$ after breakfast or lunch, with the participants in the semirecumbent position. Fetal biometry, echocardiography, and intracardiac blood flow velocity measurements were carried out using a combined two-dimensional real-time and pulsed Doppler system (Diasonics CV 400, Milpitas, CA) with a carrier frequency of $3.5 \mathrm{MHz}$ (spatial peak, temporal average intensity of less than $100 \mathrm{~mW}$ per $\mathrm{cm}^{2}$ for pulsed Doppler). Doppler studies were performed by one examiner (K. v. d. M).

Maximum Doppler flow velocity waveforms at mitral and tricuspid valve level were obtained from the four-chamber view. At outflow tract level, maximum flow velocity waveforms in the fetal ascending aorta were recorded from the five-chamber view and in the pulmonary artery from the conventional echocardiographic short axis view. Doppler sample volumes were placed immediately distal to each of the four valves and were kept as small as possible relative to the dimensions of the fetal heart with a maximum length of $0.4 \mathrm{~cm}$. The angle between the Doppler cursor and assumed flow direction was always kept below $10^{\circ}$. Flow velocities were maximized by fine transducer angulations in the azimuthal plane. To ensure the presence of fetal breathing activity throughout a Doppler flow velocity recording, fetal breathing movements still had to be present after completion of the recording. The presence of fetal breathing movements was established from rhythmic inward and outward excursions of the thoracic cage visualized on two-dimensional real-time images. Fetal apnea was defined as the absence of fetal breathing movements for $6 \mathrm{~s}$ or more. All blood flow velocity waveforms obtained during periods of apnea and breathing activity were stored on videotape. From hardcopies, analysis of five consecutive waveforms was carried out using a microcomputer (Olivetti M240) for calculation of the following parameters (mean $\pm 1 \mathrm{SD}$ ) during the inspiratory and expiratory phase of the breathing cycle and during apnea: at atrioventricular level-time-averaged velocity $(\mathrm{cm} / \mathrm{s})$, peak velocity E-wave $(\mathrm{cm} / \mathrm{s})$ and peak velocity $A$-wave $(\mathrm{cm} / \mathrm{s})$; and at outflow tract level-period time (ms), acceleration time (ms) and time-averaged velocity $(\mathrm{cm} / \mathrm{s})$.

Percentage change between inspiration and expiration was calculated for each of the flow velocity parameters according to the formula:

\section{( $F$ inspiratory phase $-F$ expiratory phase) $/$ \\ $F$ expiratory phase $* 100 \%$}

where $F$ represents the particular flow velocity parameter involved.

Regression analysis was carried out to determine differences in time-averaged flow velocity between the inspiratory and expiratory phase of the breathing cycle relative to gestational age. Differences in averaged flow velocity between periods of breathing and periods of apnea were established using the $t$ test for paired comparisons with the level of statistical significance set at 0.05 .

\section{RESULTS}

The mean period time was $426 \pm 19 \mathrm{~ms}$ (range $392-461 \mathrm{~ms}$ ) during breathing activity and $427 \pm 27$ ms (range 389-447 ms) during apnea. Data on flow velocity waveform parameters during fetal breathing and apnea as well as the percentage change between inspiration and expiration during breathing are presented in Tables 1 and 2 . The correlation coefficient $(r)$ for the change in time-averaged velocity between

Table 1. Mean $\pm 1 \mathrm{SD}$ of time-averaged velocity, peak velocity $E$ wave, and peak velocity $A$ wave during inspiratory and expiratory phases of fetal breathing movements.*

\begin{tabular}{|c|c|c|c|c|c|c|}
\hline & \multirow{2}{*}{$\begin{array}{l}\text { Insp. } \\
\text { phase }\end{array}$} & \multirow{2}{*}{$\begin{array}{l}\text { Exp. } \\
\text { phase }\end{array}$} & \multicolumn{2}{|c|}{ Change } & \multirow[b]{2}{*}{ Breathing } & \multirow[b]{2}{*}{ Apnea } \\
\hline & & & Abs. & $\%$ & & \\
\hline \multicolumn{7}{|c|}{ Mitral valve level } \\
\hline $\operatorname{TAV}(\mathrm{cm} / \mathrm{s})$ & $20.8 \pm 2.2$ & $18.2 \pm 1.8$ & $2.6 \pm 0.7$ & $10-18$ & $19.5 \pm 2.1$ & $18.6 \pm 1.6$ \\
\hline $\mathrm{E}(\mathrm{cm} / \mathrm{s})$ & $45.8 \pm 5.9$ & $34.3 \pm 4.1$ & $11.5 \pm 3.5$ & $20-63$ & $40.1 \pm 4.8$ & $38.4 \pm 4.2$ \\
\hline$A(\mathrm{~cm} / \mathrm{s})$ & $50.4 \pm 4.7$ & $47.1 \pm 3.9$ & $3.3 \pm 2.8$ & $-5-+8$ & $48.8 \pm 4.9$ & $47.8 \pm 3.6$ \\
\hline \multicolumn{7}{|c|}{ Tricuspid valve level } \\
\hline $\mathrm{TAV}(\mathrm{cm} / \mathrm{s})$ & $22.6 \pm 2.5$ & $17.0 \pm 1.7$ & $5.6 \pm 1.8$ & $17-54$ & $19.8 \pm 1.9$ & $20.1 \pm 2.0$ \\
\hline $\mathrm{E}(\mathrm{cm} / \mathrm{s})$ & $51.3 \pm 6.3$ & $38.4 \pm 4.5$ & $12.9 \pm 3.0$ & $23-42$ & $44.9 \pm 5.3$ & $43.9 \pm 4.8$ \\
\hline $\mathrm{A}(\mathrm{cm} / \mathrm{s})$ & $61.0 \pm 6.5$ & $47.5 \pm 4.8$ & $13.5 \pm 3.5$ & $19-37$ & $54.3 \pm 5.4$ & $54.4 \pm 3.6$ \\
\hline
\end{tabular}

* Including the absolute (abs.) and percentage (\%) difference between these two, during breathing and during apnea at mitral valve and tricuspid valve level.

Abbreviations: TAV, time-averaged velocity, insp., inspiratory; exp., expiratory. 
Table 2. Mean $\pm 1 \mathrm{SD}$ of acceleration time and time-averaged velocity during the inspiratory and expiratory phases of fetal breathing movements.*

\begin{tabular}{|c|c|c|c|c|c|c|}
\hline & \multirow{2}{*}{$\begin{array}{l}\text { Insp. } \\
\text { phase }\end{array}$} & \multirow{2}{*}{$\begin{array}{l}\text { Exp. } \\
\text { phase }\end{array}$} & \multicolumn{2}{|c|}{ Change } & \multirow[b]{2}{*}{ Breathing } & \multirow[b]{2}{*}{ Apnea } \\
\hline & & & Abs. & $\%$ & & \\
\hline \multicolumn{7}{|c|}{ Ascending aorta level } \\
\hline $\mathrm{AT}(\mathrm{ms})$ & $58.5 \pm 4.0$ & $58.0 \pm 4.5$ & $0.5 \pm 2.1$ & $-3-+5$ & $58.3 \pm 4.2$ & $57.6 \pm 6.3$ \\
\hline $\operatorname{TAV}(\mathrm{cm} / \mathrm{s})$ & $27.2 \pm 1.6$ & $23.5 \pm 0.9$ & $3.7 \pm 1.0$ & $8-20$ & $25.4 \pm 1.2$ & $24.4 \pm 1.2$ \\
\hline \multicolumn{7}{|c|}{ Pulmonary artery level } \\
\hline $\mathrm{AT}(\mathrm{ms})$ & $49.1 \pm 6.4$ & $48.8 \pm 4.9$ & $0.3 \pm 3.1$ & $-7-+13$ & $49.0 \pm 5.5$ & $50.4 \pm 6.2$ \\
\hline $\operatorname{TAV}(\mathrm{cm} / \mathrm{s})$ & $24.0 \pm 2.0$ & $19.6 \pm 1.3$ & $4.0 \pm 1.5$ & $12-31$ & $21.8 \pm 1.5$ & $21.9 \pm 1.4$ \\
\hline
\end{tabular}

* Including absolute (abs.) and percentage (\%) change between these two, during breathing and during apnea in the ascending aorta and pulmonary artery.

Abbreviations: AT, acceleration time; TAV, time-averaged velocity.

inspiration and expiration relative to gestational age was $0.55(p=0.06)$ and $0.46(p=0.13)$ at mitral and tricuspid valve level, and $0.70(p=0.01)$ and $0.88(p$ $=0.0002)$ at ascending aorta and pulmonary artery level, respectively. Time-averaged velocity at mitral valve and ascending aorta level was significantly higher during breathing than during apnea, mean differences being $0.85 \pm 0.71 \mathrm{~cm} / \mathrm{s}(p=0.002)$ and 0.94 $\pm 0.44 \mathrm{~cm} / \mathrm{s}(p=0.001)$, respectively. No such difference was observed at tricuspid valve and pulmonary artery level with time-averaged velocity differences of $0.33 \pm 1.12 \mathrm{~cm} / \mathrm{s}(p=0.3)$ and $0.09 \pm 1.15 \mathrm{~cm} / \mathrm{s}(p$ $=0.8$ ).

\section{COMMENT}

To our knowledge, this is the first quantitated study on breathing related cardiac flow velocity changes in the human fetus. Period times during fetal breathing activity and apnea reflected normal fetal heart rates between 130 and $155 \mathrm{bpm}$. Clear changes in time-averaged flow velocities relative to inspiration and expiration occurred at all four cardiac valve levels. The percentage change in time-averaged velocity varied between $10 \%$ and $54 \%$ at atrioventricular level and between $8 \%$ and $31 \%$ in the cardiac outflow tracts. We suggest that these breathing-related velocity changes are determined by changes in venous return as a result of fluctuations in intrathoracic pressure during fetal breathing activity. Breathing related changes in time-averaged velocity increased with advancing gestational age at outflow tract level and to a lesser extent at atrioventricular level. A similar observation was done in the ductus arteriosus (van Eyck et al. 1990) and may be partly explained by the reduction in downstream impedance at umbilical placental level during the third trimester of pregnancy.

Acceleration time at outflow tract level demonstrated very little change when related to inspiration and expiration. Acceleration time is mainly determined by arterial afterload, which is less subject to fluctuations by breathing activity than the venous preload.

When considering the $E$ and $A$ wave of the atrioventricular valves separately, it appears that the $E$ wave representing the passive atrial filling phase is changed at both sides of the heart; for the A wave, this is only so for the tricuspid valve. At mitral valve level, virtually no change in atrial contraction occurs during fetal breathing activity. This observation is difficult to explain because we have no direct access to variables that may affect atrial contraction, in particular afterload.

Of interest is that the time-averaged flow velocity at the level of the mitral valve and ascending aorta was significantly higher during fetal breathing movements than during apnea. Volume flow equals time-averaged flow velocity multiplied by vessel area. Although valve areas are unknown in the present study, it is unlikely that they change considerably as a result of breathing activity. If this is so, then the raised timeaveraged flow velocities on the left side of the heart suggest increased left ventricular output in the presence of fetal breathing movements. Of interest is the recent observation of raised flow velocities suggesting increased shunting of blood through the foramen ovale during fetal breathing activity (van Eyck et al. 1991). Because increased left ventricular output would benefit cerebral blood supply, one may speculate on the role of fetal breathing movements in maintaining blood supply to the vital organs.

Both postnatal animal experiments (Summer et al. 1979) and postnatal human intracardiac Doppler flow studies (Dabestani et al. 1988) have unanimously demonstrated that during inspiration, stroke volume at tricuspid valve and pulmonary artery level increases, whereas stroke volume at mitral valve and ascending aorta level decreases. Conversely, during 
expiration, right heart stroke volume decreases, whereas left heart stroke volume increases. Obviously, the intrauterine and postnatal situation cannot be compared because of the intrauterine nonfunctioning of the lungs and the presence of right-to-left shunting at foramen ovale and ductus arteriosus level. These data show, however, that breathing may cause impressive changes in cardiac hemodynamics.

Finally, from the present study, it has become clear that in order to assure a steady-state situation during fetal cardiac flow velocity waveform recordings, these should be collected during fetal apnea.

\section{REFERENCES}

Dabestani, A.; Takenaka, K.; Allen, B.; Gardin, J. M.; Fischer, S.; Russell, D.; Henry, W. L. Effects of spontaneous respiration on diastolic left ventricular filling assessed by pulsed Doppler echocardiography. Am. J. Cardiol. 61:1356-1358; 1988.

de Vries, J. I. P.; Visser, G. H. A.; Prechtl, H. F. R. The emergence of fetal behaviour I. Qualitative aspects. Early Hum. Dev. $7: 301-322 ; 1982$.
Kloosterman, G. On intrauterine growth. Int. J. Gynaecol. Obstet. $8: 895-901 ; 1970$.

Marsal, K.; Lindblad, A.; Lingman, G. Blood flow in the fetal descending aorta; intrinsic factors affecting fetal blood flow, i.e., fetal breathing movements and fetal cardiac arrhythmia. Ultrasound Med. Biol. 10:339-348; 1984

Natale, R.; Nasells-Paterson, C.; Connors, G. Patterns of fetal breathing activity in the human fetus at 24 to 28 weeks of gestation. Am. J. Obstet. Gynecol. 158:317-321; 1988.

Summer, W. R.; Permutt, S.; Sagawa, K.; Shoukas, A. A.; Bromberger-Barnea, $B$. Effects of spontaneous respiration on canine left ventricular function. Circ. Res. 45:719-728; 1979.

Trudinger, B. J.; Aust, F.; Knight, P. C. Fetal age and patterns of human fetal breathing movements. Am. J. Obstet. Gynecol. 137:724-728: 1980 .

van Eyck, J.; Stewart, P. A.; Wladimiroff, J. W. Human fetal foramen ovale flow velocity waveforms relative to fetal breathing movements in normal term pregnancies. J. Ultrasound Obstet. Gynecol. 1:5-8; 1991.

van Eyck, J.; van der Mooren, K.; Wladimiroff, J. W. Ductus arteriosus flow velocity modulation by fetal breathing movements as a measure of fetal lung development. Am. J. Obstet. Gynecol. $163: 558-566: 1990$.

Walker, A. M. Physiological control of the fetal cardiovascular system. In: Beard, R. W.; Nathanielz, P. W., eds. Fetal physiology and medicine. The basis of perinatology. London: Butterworth; 1984:297-316. 